Int. J. Electrochem. Sci., 15 (2020) 12136 - 12148

Mini review

\title{
Electrochemical Biosensors for MicroRNA Detection using Duplex-Specific Nuclease based Signal Amplification Strategies
}

\author{
Daohong $W u^{1}$, Xinyao $\mathrm{Yi}^{1, *}$ and Ning $\mathrm{Xia}^{2, *}$ \\ ${ }^{1}$ College of Chemistry and Chemical Engineering, Central South University, Changsha, Hunan \\ 410083, People's Republic of China \\ ${ }^{2}$ Henan Province of Key Laboratory of New Optoelectronic Functional Materials, Anyang Normal \\ University, Anyang, Henan 455000, People's Republic of China \\ *E-mail: yixinyao@csu.edu.cn (X.Y.); xianing82414@csu.edu.cn (N.X.)
}

doi: $10.20964 / 2020.12 .67$

Received: 2 September 2020 / Accepted: 12 October 2020 / Published: 31 October 2020

\begin{abstract}
MicroRNAs (miRNAs) play an important function in physiological and pathological processes. They have attracted extensive attention and become the important breakthrough in tumor diagnosis and clinical treatment. In recent years, many sensitive and accurate detection techniques in vitro have been proposed for the quantification of miRNAs. Duplex-specific nuclease (DSN) displays considerable cleavage preference for DNA in the DNA/RNA hybrid. This paper reviewed the progress in electrochemical detection of miRNAs based on the DSN-assisted signal amplification.
\end{abstract}

Keywords: microRNA; electrochemistry; duplex-specific nuclease; signal amplification

\section{FULL TEXT}

(C) 2020 The Authors. Published by ESG (www.electrochemsci.org). This article is an open access article distributed under the terms and conditions of the Creative Commons Attribution license (http://creativecommons.org/licenses/by/4.0/). 